\title{
Relation between speaking space of the /s/ sound and freeway space in dentate and edentate subjects
}

\section{Correlação entre espaço de pronúncia do som /s/e espaço funcional livre em indivíduos dentados e edentados}

\author{
Raphael Freitas de Souza* \\ Marco Antonio Compagnoni**
}

\begin{abstract}
The purpose of this study is to assess the relation between the speaking space of the /s/ sound and the freeway space in two subject groups. One group had natural dentition (Group I, n =61) and the other comprised complete denture wearers (Group II, $n=33$ ). The analysis was done by means of a jaw-tracking device (K6-I Diagnostic System, Myotronics Research Inc., Seattle, WA, USA). Freeway space was determined by asking the subjects to occlude from the postural rest position. Speaking space of /s/ was measured during the pronunciation of the word "seis" and comprised the mean distance from the /s/ speaking position to maximal intercuspation. A weak correlation was found between the speaking space of $/ \mathrm{s} /$ and the freeway space in Group I $(r=0.41$, $\mathrm{p}<0.01)$, but in Group II, the correlation was stronger $(\mathrm{r}=0.75, \mathrm{p}<0.01)$. The speaking space of $/ \mathrm{s} /$ and freeway space were different in Group I, but statistically similar in Group II (paired $t$-test, $\alpha=0.05$ ). It can be suggested that anatomic changes following prosthetic procedures caused a functional adaptation which resulted in more similar values for the speaking space of /s/ and the freeway space.
\end{abstract}

DESCRIPTORS: Phonetics; Dental occlusion; Denture, complete; Jaw relation record.

RESUMO: O objetivo deste estudo foi investigar a associação entre o espaço de pronúncia do som /s/ e o espaço funcional livre em dois grupos de indivíduos. A amostra foi classificada em dentados (Grupo I, $\mathrm{n}=61$ ) e portadores de próteses totais (Grupo II, $\mathrm{n}=33$ ). A análise foi realizada empregando um instrumento cinesiográfico (K6-I Diagnostic System, Myotronics Research Inc., Seattle, WA, EUA), capaz de fornecer registros dos movimentos mandibulares. O espaço funcional livre foi determinado solicitando-se ao indivíduo que ocluísse a partir da posição de repouso postural. O espaço de pronúncia do /s/ foi aferido durante a pronúncia da palavra "seis", registrado como a posição mandibular média para o som /s/ em relação à máxima intercuspidação. Houve uma fraca correlação entre o espaço funcional livre e o espaço de pronúncia do / $/$ para o Grupo I $(\mathrm{r}=0,41, \mathrm{p}<0,01)$, mas uma correlação relativamente forte para o Grupo II $(\mathrm{r}=0,75, \mathrm{p}<0,01)$. O espaço funcional livre e o espaço de pronúncia do /s/ foram diferentes no Grupo I, mas estatisticamente semelhantes no Grupo II (teste $t$ pareado, $\alpha=0,05$ ). Dessa forma, pode-se deduzir que mudanças anatômicas após o procedimento protético provocaram uma adaptação funcional, sendo que esse processo adaptativo aproximou as duas variáveis - espaço de pronúncia do /s/ e espaço funcional livre.

DESCRITORES: Fonética; Oclusão dentária; Prótese total; Registro da relação maxilomandibular.

\section{INTRODUCTION}

Determination of the occlusal vertical dimension (OVD) is regarded as being particularly important during treatment with complete dentures. There are several techniques to establish OVD, but no single one has proven superior to the oth$\mathrm{ers}^{19}$. These techniques include the use of the rest interocclusal distance ${ }^{16,17}$ and the use of phonet$\operatorname{ics}^{18,22}$.

The assessment using the resting position is based on the induction of mandibular relaxation $^{16,17}$. The resting vertical dimension is meas- ured and the OVD is considered to be 2 to $4 \mathrm{~mm}$ smaller than this dimension ${ }^{20}$. Although this method is objective, mandibular resting position is not static. It varies with changes in the OVD in complete denture wearers, as found by Tallgren ${ }^{23}$ (1957).

It has been suggested that the mandibular position during the pronunciation of sibilant sounds can be used to establish OVD ${ }^{18,22}$. It was proposed that an interocclusal space of 1 to $2 \mathrm{~mm}$ should be found during the pronunciation of these sounds.

\footnotetext{
*PhD Student; **Chairman - Department of Dental Materials and Prosthodontics, School of Dentistry of Araraquara, São Paulo State University.
} 
Souza RF, Compagnoni MA. Relation between speaking space of the /s/ sound and freeway space in dentate and edentate subjects. Braz Oral Res 2004;18(4):333-7.

In addition, it was stated that speech positions are not affected by the removal of teeth ${ }^{13}$. Nevertheless, Burnett ${ }^{3}$ (2000) found that the closest speaking space of subjects who suffered severe anterior toothwear is smaller than that in the control group. This finding indicates a functional adaptation to toothwear. Although these findings may be significant, it is unknown whether this adaptation occurs with the edentulous predicament.

One of the hypotheses underlying the phonetic method is that the position of the mandible during the pronunciation of sibilant sounds should be the same before and after oral rehabilitation ${ }^{19}$. Unfortunately, this hypothesis has not yet been critically tested ${ }^{19}$ and it is doubtful whether the mandibular position during speech remains unchanged after complete denture insertion.

Thus, it is proposed that assessment of resting and speaking positions does not provide a reliable guide to accurate approximation of original OVD ${ }^{3}$. Adaptation to a new OVD could alter both the resting position and the mandibular position needed to say the /s/ sound. The aim of this investigation was to evaluate the interocclusal distance during the pronunciation of a sibilant sound (/s/) and during rest in dentate and edentate subjects.

\section{MATERIALS AND METHODS Subjects}

A total of 94 individuals participated in the study and were divided into two groups. No subject suffered from any speech defect or exhibited any signs or symptoms of temporomandibular disorders. All the participants had good general and oral health. This research project was approved by the institutional Ethics Committee. All participants were informed on the nature of the investigation and agreed to take part in it.

Group I comprised 61 subjects $(25$ men and 36 women) with mean age of 30.26 years $( \pm 12.71)$. All subjects had complete dentition, except for those who did not have the third molars. The participants presented stable maximal intercuspation and had no fixed or removable prosthetic restorations or orthodontic appliances.

Group II comprised 33 edentate subjects (10 men and 23 women) with mean age of 59.18 years $( \pm 10.00)$. The subjects had been wearing the same pair of conventional complete dentures from six to twenty-four months. The prostheses were clinically adequate, in terms of retention, stability and support, and satisfactory to the participants. All of these participants were treated at the Department of Dental Materials and Prosthodontics, School of Dentistry of Araraquara. Vertical dimension assessment was performed as follows: each subject was instructed to reach the resting position after licking the lips, swallowing and saying $/ \mathrm{m} /$. This procedure was repeated three times and the mean distance from the chin to the base of the nose, minus $3 \mathrm{~mm}$, was considered the OVD. Following these measurements, an esthetic appraisal was done with the occlusion rims in position. Finally, the OVD was assessed by a phonetic method $^{22}$. The occlusion rims were not allowed to touch each other during the pronunciation of sibilant sounds.

\section{Kinesiographic equipment}

Jaw positions were recorded using a mandibular kinesiograph (K6-I Diagnostic System, Myotronics Research Inc., Seattle, WA, USA). This equipment consisted of an array of sensors secured to the subject's head that provided information on mandibular movements from the incisor point. When the mandible moved, the sensors tracked a small bar magnet attached to the buccal midline surface of the lower central incisors. This procedure was similar for both groups. The kinesiograph was connected to a computerized system that records and displays spatial coordinates in the vertical and anteroposterior axes to the nearest $0.1 \mathrm{~mm}$.

\section{Research protocol}

The participants were evaluated in a single session. They sat upright on a dental chair with the head unsupported. All subjects were instructed to keep their heads as steady as possible during recording.

Freeway space (FS) was obtained for each subject as they were instructed to place the mandible in the resting position and then occlude on their back teeth. Mandibular resting was assessed as the participants were asked to swallow and then relax their jaw. When there was constant tracing of the mandibular position for 6 seconds observed on the computer monitor, the records were made. Following the resting position recording, each subject was asked to place the mandible in its position of maximal intercuspation (MI). FS records described the mandibular movement from the resting position to MI on the vertical and anteroposterior axes. This measure was performed three times and the mean value was calculated. 
Souza RF, Compagnoni MA. Relation between speaking space of the /s/ sound and freeway space in dentate and edentate subjects. Braz Oral Res 2004;18(4):333-7.

Subsequently, the speaking space of / s / (SSS) was evaluated. It can be defined as the mandibular movement from the emission of the /s/ sound to maximal intercuspation. Each participant was asked to repeat the word "seis" three times at normal conversation rate and volume. This word contains the consonant sound / s / twice, which provides six records. Individual values comprised the mean of six measures. The tracing described each axis separately. Thus, two measures were collected: vertical and anteroposterior.

Kinesiographic analysis provides FS and SSS measurements on distinct axes, but does not measure how much the mandible moves in oblique orientation (resulting movement). This movement was calculated by Pythagoras' equation $\left(a^{2}=b^{2}+c^{2}\right.$, where " $a$ " is the resulting value, " $b$ " is the mean value on the vertical axis and "c" is the mean movement on the anteroposterior axis).

The statistical analysis was carried out by means of the Student's $t$-test for paired data and Pearson's correlation test. The analysis measured the difference and the relation between the values recorded for FS and SSS. The level of significance was $\mathrm{p}<0.05$. Data were evaluated using the software SPSS for Windows - Version 7.5.1, 1996 (SPSS Inc., Chicago, IL, USA).

\section{RESULTS}

Table 1 shows the mean values of FS and Table 2 shows the mean values of SSS.

The FS and SSS relationship was evaluated by two tests. The two variables were compared for each group by a paired $t$-test. The relation between FS and SSS was measured by Pearson's correlation test. Thus, wider SSS were correlated to higher FS for both Groups I and II. The results of the tests are shown in Tables 3 to 5 . Graphs 1 and 2 present a combined graphic analysis of the two variables.

\section{DISCUSSION}

The relationship between FS and SSS for a group of subjects with healthy dentition was found to be different from that of a group of complete denture wearers. The dimension of FS was reduced in comparison with that of SSS in Group I. Nonetheless, the mean SSS of Group II was not different from the mean FS. Both the /s/ sound and the resting positioning placed the mandible at a posterior position in this group. This retrusion did not occur in most of the dentate participants.
TABLE 1 - Mean values for FS (in $\mathrm{mm}$; \pm standard deviation) according to vertical and anteroposterior axes and resulting measures.

\begin{tabular}{l|r|r}
\hline \hline \multicolumn{1}{c|}{ Axes } & \multicolumn{1}{c|}{ Group I } & \multicolumn{1}{c}{ Group II } \\
\hline Vertical & $1.48( \pm 1.10)$ & $2.05( \pm 1.06)$ \\
\hline Anteroposterior & $-0.17 \pm 0.67)$ & $-1.08( \pm 0.54)$ \\
\hline Resulting & $1.59( \pm 1.17)$ & $2.34( \pm 1.15)$ \\
\hline \hline
\end{tabular}

FS: freeway space.

TABLE 2 - Mean values for SSS (in $\mathrm{mm}$; \pm standard deviation) according to vertical and anteroposterior axes and resulting measures.

\begin{tabular}{l|c|r}
\hline \hline \multicolumn{1}{c|}{ Axes } & Group I & \multicolumn{1}{c}{ Group II } \\
\hline Vertical & $1.79( \pm 1.17)$ & $2.50( \pm 1.37)$ \\
\hline Anteroposterior & $0.90( \pm 1.18)$ & $-0.70( \pm 0.78)$ \\
\hline Resulting & $2.23( \pm 1.35)$ & $2.67 \pm 1.47)$ \\
\hline \hline
\end{tabular}

SSS: speaking space of $/ \mathrm{s} /$.

TABLE 3 - Paired data $t$-test between SSS and FS. Probability values (p) for Group I and Group II.

\begin{tabular}{l|c|c|c}
\hline & SSS and \\
Groups & Vertical & Anteroposterior & Resulting \\
\hline Group I & $0.04^{*}$ & $0.00^{* *}$ & $0.00^{* *}$ \\
\hline Group II & $0.01^{* *}$ & $0.00^{* *}$ & 0.06 \\
\hline \hline
\end{tabular}

*Significant at a $5 \%$ level. ${ }^{* *}$ Significant at a $1 \%$ level. FS: freeway space. SSS: speaking space of $/ \mathrm{s} /$.

TABLE 4 - Pearson's correlation test results for Group I (n=61). SSS and FS.

\begin{tabular}{|c|c|c|c|}
\hline $\mathrm{FS} \quad \mathrm{SSS}$ & Vertical & Anteroposterior & Resulting \\
\hline Vertical & $0.45^{* *}$ & - & - \\
\hline $\begin{array}{l}\text { Anteropos- } \\
\text { terior }\end{array}$ & - & $0.51^{* *}$ & - \\
\hline Resulting & - & - & $0.41^{* *}$ \\
\hline
\end{tabular}

** Significant at a $1 \%$ level. FS: freeway space. SSS: speaking space of $/ \mathrm{s} /$.

TABLE 5 - Pearson's correlation test results for Group II $(\mathrm{n}=33)$. SSS and FS.

\begin{tabular}{|c|c|c|c|}
\hline $\mathrm{FS} \quad \mathrm{SSS}$ & Vertical & Anteroposterior & Resulting \\
\hline Vertical & $0.75^{* *}$ & & \\
\hline $\begin{array}{l}\text { Anteropos- } \\
\text { terior }\end{array}$ & - & $0.68^{* *}$ & \\
\hline Resulting & - & - & $0.75^{* *}$ \\
\hline
\end{tabular}

** Significant at a $1 \%$ level. FS: freeway space. SSS: speaking space of $/ \mathrm{s} /$. 
Souza RF, Compagnoni MA. Relation between speaking space of the /s/ sound and freeway space in dentate and edentate subjects. Braz Oral Res 2004;18(4):333-7.

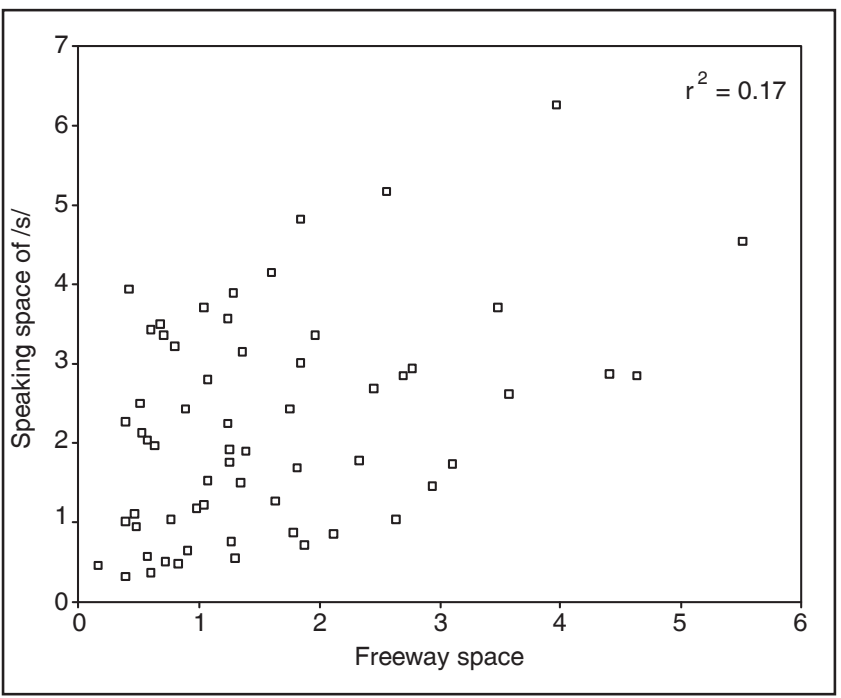

GRAPH 1 - Dispersion diagram between speaking space of / $/$ (SSS) and freeway space (FS) (in $\mathrm{mm}$ ) for Group I.

There is a widespread belief that the speaking space of sibilant sounds is smaller than the freeway space. The present study questions this belief, since it was found that the inverse was true. It was stated that the closest speaking space is greater than the FS in dentate subjects ${ }^{10,14}$. Similarities between SSS and FS were shown in several studies $^{3,8,12,21}$. However, no previous report showed that the FS was greater than the SSS.

A weak correlation between FS and SSS was found in Group I whereas Gillings ${ }^{8}$ (1973) and Burnett $^{4}$ (1994) found no association between FS and the closest speaking space in dentate subjects. Nevertheless, the FS-SSS correlation was found to be strong in Group II. It can be inferred that the interocclusal space during the /s/ sound pronunciation is highly related to the mandibular resting position in complete denture wearers.

The SSS and FS relation and comparison analyses indicated that phonetic adaptation to complete dentures occurred for Group II subjects. It can be inferred that both variables can be affected by alterations in the oral environment. The adaptability of the freeway space has been described in previous studies ${ }^{5,11,15,23}$. However, the speaking spaces of complete denture wearers had not yet been described. If the form of the oral cavity is modified, the subject will be compelled to change his/her method of articulating a sound to some extent. Complete denture treatment causes these alterations ${ }^{2}$. Edentulous patients are found to speak progressively better after receiving new dentures

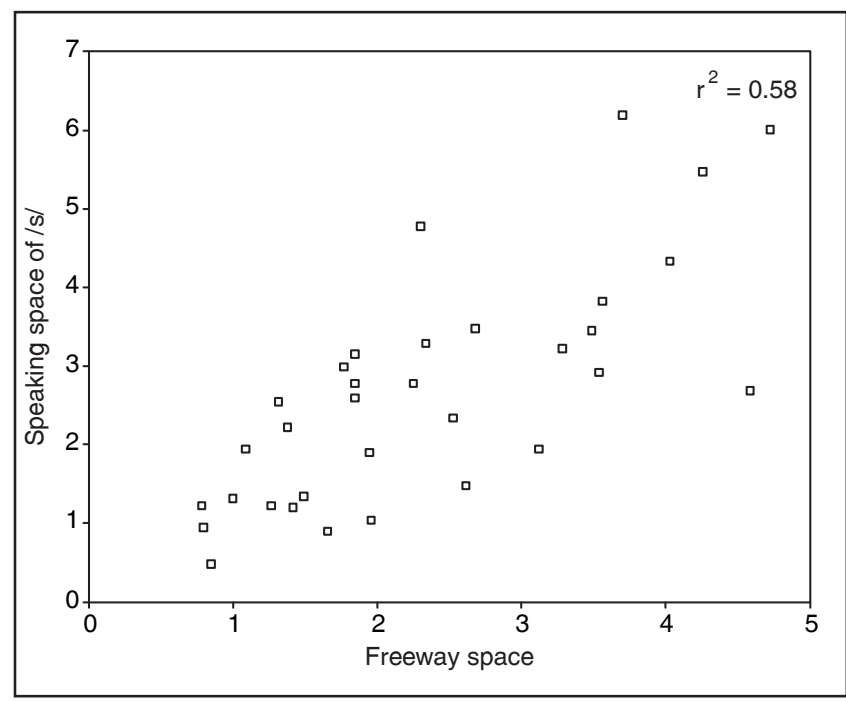

GRAPH 2 - Dispersion diagram between speaking space of /s / (SSS) and freeway space (FS) (in mm) for Group II.

than at the insertion appointment. This stresses the adaptability of the articulatory organs to compensate for changes ${ }^{1,24}$. Functional adaptation was also shown for a group of subjects with severe toothwear. A cross-sectional study found that the closest speaking space in this group was reduced in comparison with that in a control group ${ }^{3}$. In other words, this reflects an adaptation to a slowly modified incisal relationship.

For the anteroposterior movement, Group I and Group II showed distinct behaviors. While dentate subjects tended towards protrusion during the / s / pronunciation, denture wearers tended towards retrusion. This finding was regarded as an adaptive postural change resulting from a new configuration in mandibular and tongue positions during speech. Chaney et al. ${ }^{6}$ (1978), using lateral cephalometric radiographs, stated that the tongue and mandible are positioned more inferiorly after immediate complete denture insertion during the /s / pronunciation, when compared to the preextraction condition. However, the author found that the mandible returns to its original position after four weeks.

An individual who has changed from natural dentition to dentures has to adapt to artificial situations, i.e., the absence of tooth proprioception affects the precision of speech movement for the pronunciation of $/ \mathrm{s} /{ }^{7}$. Based on our results we can imply that SSS and FS are affected by the changes in the oral cavity in a similar way. However, this 
Souza RF, Compagnoni MA. Relation between speaking space of the /s/ sound and freeway space in dentate and edentate subjects. Braz Oral Res 2004;18(4):333-7.

study cannot address the cause/effect relationships due to its cross-sectional design.

The wide inter-individual variability of SSS supports that this method has low specificity. In other words, SSS-based speech methods cannot identify if the patient has reduced OVD or an ample speaking space. A more interesting indication is the evaluation of whether or not there is increased OVD, as stated by Gittelson ${ }^{9}$ (2002). This means that interocclusal relations of trial dentures can be assessed by sibilant sounds, as long as this method's limitations are taken into account.

Within the limits of this study, we can infer that mandibular positions during speech change in response to complete denture wearing. However, more studies are needed to stress the actual relevance of the speech methods for OVD establishment. Other conditions to be studied are the presence of removable partial dentures and implant-supported overdentures.

\section{REFERENCES}

1. Agnello JG, Wictorin L. A study of phonetic changes in edentulous patients following complete denture treatment. J Prosthet Dent 1972;27:133-9.

2. Bond EK, Lawson WA. Speech and its relation to dentistry. I. Speech and speech defects. Dent Pract Dent Rec 1968;19:75-82.

3. Burnett CA. Clinical rest and closest speech positions in the determination of occlusal vertical dimension. J Oral Rehabil 2000;27:714-9.

4. Burnett CA. Reproducibility of the speech envelope and interocclusal dimensions in dentate subjects. Int J Prosthodont 1994;7:543-8.

5. Carlsson GE, Ingervall B, Kocak G. Effect of increasing vertical dimension on the masticatory system in subjects with natural teeth. J Prosthet Dent 1979;41:284-9.

6. Chaney SA, Moller KT, Goodkind RJ. Effects of immediate dentures on certain structural and perceptual parameters of speech. J Prosthet Dent 1978;40:8-12.

7. Ghi H, McGivney GP. Influence of tooth proprioception on speech articulation. J Prosthet Dent 1979;42:609-13.

8. Gillings BRD. Jaw movements in young adult men during speech. J Prosthet Dent 1973;29:567-76.

9. Gittelson GL. Vertical dimension of occlusion in implant dentistry: significance and approach. Implant Dent 2002;11:33-40.

10. Howell PGT. Incisal relationship during speech. J Prosthet Dent 1986;56:93-9.

11. Ismail YH, George WA, Sassouni V, Scott RH. Cephalometric study of the changes occurring in the face height following prosthetic treatment. I. Gradual reduction of both occlusal and rest face heights. J Prosthet Dent 1968;19:321-30.

12. Lu GH, Chow TW, So LKH, Clark RKF. A computeraided study of speaking spaces. J Dent 1993;21:289-96.

\section{CONCLUSIONS}

1. The correlation between FS and SSS was found to be weak in dentate subjects.

2. The correlation between FS and SSS was strong in complete denture wearers.

3. Results among edentulous subjects suggested that structural changes following prosthetic procedures caused a functional adaptation that resulted in more similar values for SSS and FS.

\section{ACKNOWLEDGMENTS}

This research was supported by the National Council for Scientific and Technological Development (CNPq) (grant no. 1311340/2001-8) and the State of São Paulo Research Foundation (FAPESP) (grant no. 01/06159-4). We also thank Solange Aranha for proofreading the English version.

13. Mehringer EJ. The use of speech patterns as an aid in prosthodontic reconstruction. J Prosthet Dent 1963;13:825-36.

14. Miralles R, Dodds C, Palazzi C, Jaramillo C, Quezada $\mathrm{V}$, Ormeno G, et al. Vertical dimension. Part 1: comparison of clinical freeway space. Cranio 2001;19:230-6.

15. Nairn RI, Cutress TW. Changes in mandibular position following removal of the remaining teeth and insertion of immediate complete dentures. Br Dent J 1967;122:303-6.

16. Niswonger $\mathrm{ME}$. The rest position of the mandible and the centric relation. J Am Dent Assoc 1934;21:1572-82.

17. Pleasure MA. Correct vertical dimension and freeway space. J Am Dent Assoc 1951;43:160-3.

18. Pound E. Let /S/ be your guide. J Prosthet Dent 1977; 38:482-9.

19. Rivera-Morales WC, Mohl ND. Relationship of occlusal vertical dimension to the health of the masticatory system. J Prosthet Dent 1991;65:547-53.

20. Rivera-Morales WC, Mohl ND. Restoration of the vertical dimension of occlusion in the severely worn dentition. Dent Clin North Am 1992;36:651-64.

21. Rivera-Morales WC, Mohl ND. Variability of closest speaking space compared with interocclusal distance in dentulous subjects. J Prosthet Dent 1991;65:228-32.

22. Silverman MM. The speaking method in measuring vertical dimension. J Prosthet Dent 1953;3:193-9.

23. Tallgren A. Changes in adult face height due to aging, wear and loss of teeth and prosthetic treatment. Acta Odontol Scand 1957;15:1-122.

24. Tanaka H. Speech patterns of edentulous patients and morphology of the palate in relation to phonetics. $J$ Prosthet Dent 1973;29:16-28.

Received for publication on Nov 06, 2003

Sent for alterations on Aug 02, 2004

Accepted for publication on Sep 24, 2004 